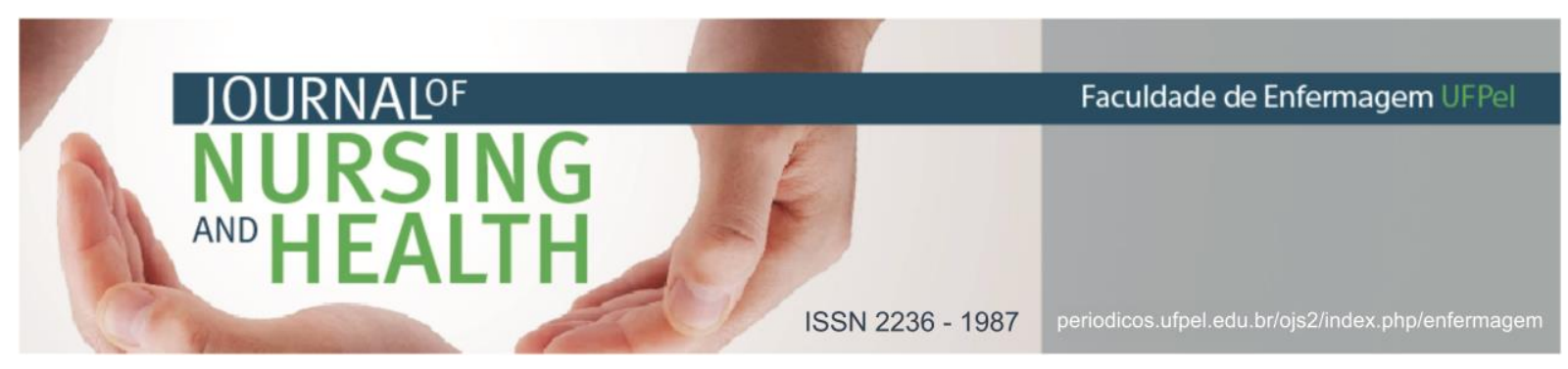

ARTIGO ORIGINAL

\title{
Violência contra a mulher: a percepção dos graduandos de enfermagem
}

\author{
Violence against women: how nursing students perceive it
}

\author{
Violencia contra la mujer: la percepción de estudiantes de enfermería
}

Sobrinho, Natália Costa ${ }^{1}$; Kasmirsck, Cristine²; Soares, Joannie Soares dos Santos Fachinelli³; Pinheiro, Monalisa da Silva ${ }^{4}$; Fioravanti Junior, Geferson Antonio ${ }^{5}$

Como citar este artigo: Sobrinho NC, Kasmirsck C, Soares JSSF, Pinhero MS, Fioravanti Junior GA. Violência contra a mulher: a percepção dos graduando de enfermagem. J. nurs. health. 2019;9(1):e199102

\section{RESUMO}

Objetivo: conhecer as percepções dos graduandos em Enfermagem sobre violência contra a mulher. Métodos: estudo qualitativo realizado com 16 graduandos em Enfermagem entre abril e junho de 2016. Dados coletados por entrevista e realizada a análise de conteúdo. Resultados: foram determinadas como categorias: entendimento sobre violência de gênero, abordagem da violência de gênero na formação dos graduandos, percepção sobre a atuação do enfermeiro na atenção às mulheres em situação de violência e considerações sobre o atendimento ideal à mulher em situação de violência. Considerações finais: a violência e a desigualdade de gênero são percebidas pelos acadêmicos. O papel do enfermeiro é destacado nas habilidades de comunicação e acolhimento. Os graduandos não se identificam como parte da equipe de saúde que receberá a mulher em situação de violência e percebem o tema no currículo da graduação. Estudos semelhantes contribuirão com a discussão sobre a violência contra a mulher.

Descritores: Enfermagem; Estudantes de enfermagem; Violência contra a mulher.

\section{ABSTRACT}

Objective: to learn how nursing graduate students perceive violence against women. Methods: qualitative analysis carried out with 16 nursing students from April to June 2016. Data were collected in interviews and content was analyzed. Results: four categories were discerned: overall understanding about gender-related violence; approach towards gender-related violence during student's graduation; perception about nurse's role when assisting violated women; considerations about the best approach to take when assisting violated women. Final considerations: genderrelated violence is noticed by students, as much as gender inequality. Nurse's highlighted role is the

1 Enfermeira. Centro Universitário Metodista do IPA. E-mail: natalia.sobrinho@gmail.com http://orcid.org/00000001-6043-8125

2 Enfermeira. Mestra em Endocrinologia. Centro Universitário Metodista do IPA. E-mail: cristinekas@yahoo.com.br http://orcid.org/0000-0002-5391-4362

3 Enfermeira. Doutora em Enfermagem. Universidade do Vale do Rio dos Sinos (UNISINOS). E-mail: joanniefs@unisinos.br http://orcid.org/0000-0001-7308-8048

4 Enfermeira. Doutora em Enfermagem. Universidade do Vale do Rio dos Sinos (UNISINOS). E-mail: monalisap@unisinos.br http://orcid.org/0000-0002-0673-5003

5 Enfermeiro. Mestre em Ciências da Saúde. Centro Universitário Metodista do IPA. Universidade do Vale do Rio dos Sinos (UNISINOS). E-mail: gfioravanti@unisinos.br http://orcid.org/0000-0002-4960-8581 




ability to communicate and to foster patient care. Undergraduate students do not identify as active part of health care team. However, they identify the theme in the University's undergraduation syllabus. Similar researches can contribute to discuss violence against women.

Descriptors: Nursing; Students, nursing; Violence against women.

\section{RESUMEN}

Objetivo: conocer las percepciones de los estudiantes de enfermería sobre la violencia contra la mujer. Metodología: estudio cualitativo realizado con 16 estudiantes entre abril y junio de 2016. Datos recolectados por medio de entrevistas y cumplido el análisis de contenido. Resultados: se determinaron 4 categorías: comprehensión de la violencia de género, abordaje de la violencia de género en la formación de los estudiantes, percepción de la actuación del enfermero en la atención a las mujeres en situación de violencia y consideraciones sobre la atención ideal a la mujer en situación de violencia. Consideraciones finales: la violencia de género y la desigualdad son percibidas por los académicos. El papel del enfermero se destaca por sus habilidades de comunicación y aceptación. Los estudiantes no se identifican como parte activa de la rama de la salud. Identifican el tema en el currículo de pregrado. Estudios similares pueden contribuir sobre este tema.

Descriptores: Enfermería; Estudiantes de enfermería; Violencia contra la mujer.

\section{INTRODUÇÃO}

A violência contra a mulher é considerada um problema global e que atinge, mundialmente, uma a cada três mulheres. 0 termo violência contra mulher traduz as diversas formas de violência, incluindo violência por parceiros íntimos, seja física, sexual ou psicológica, bem como outros tipos de violência como mutilações, assassinatos e tráfico de mulheres. ${ }^{1}$

Embora a violência possa ocorrer em diferentes cenários e culturas, constata-se que a mulher mais jovem, com baixa escolaridade e baixa renda, apresenta riscos aumentados de sofrer violência. 0 agressor frequentemente tem relação íntima com a vítima, bem como, faz uso de substâncias, como o álcool no momento da agressão. ${ }^{2}$

A violência contra a mulher é entendida sob a perspectiva de gênero e ocorre contra uma pessoa que não é considerada igual ou que não tenha as mesmas condições de existência e valor. A violência é motivada quando as relações de desigualdade de acordo com as condições de sexo são percebidas, sobretudo no âmbito familiar, no qual as relações se constituem por hierarquias. ${ }^{3}$

A subjetividade das questões de gênero, associadas ao fato do masculino ter mais poder sobre 0 feminino em nossa sociedade revelam uma dificuldade da identificação da violência, sobretudo, se as tipificações de violência não são claramente reconhecidas na legislação vigente. ${ }^{4} \mathrm{~A}$ Lei Maria da Penha reafirma a amplitude e a diversidade desse tipo de violência, criando mecanismos jurídicos para coibir e punir a violência contra a mulher, ampliando o olhar sobre esse contexto para promover a segurança da mulher. ${ }^{5}$

0 relatório final da Comissão Parlamentar Mista de Inquérito (CPMI) da Violência contra a Mulher, publicado em junho de 2013, teve como objetivo contribuir para que os Poderes Executivo, Legislativo e Judiciário, de todas as esferas 


\section{JOURNALOF \\ NURSING \\ AND}

administrativas, possam elaborar políticas e ações que permitam enfrentar as diversas formas de violências que atingem as mulheres brasileiras. Deste trabalho nasceram 73 recomendações para os 17 estados e - Distrito Federal. Dentre elas, considerar o feminicídio como um agravante do homicídio com pena de 22 a 30 anos de prisão. ${ }^{6}$

Devido a inúmeros fatores emocionais envolvidos, tais como o medo ou a vergonha de assumir a situação de violência, rastrear, notificar e atender essas mulheres se torna uma tarefa ainda mais delicada. De acordo com dados do Sistema de Informações e Agravos de Notificação (SINAN), em 2014 foram registrados 223,76 atendimentos relacionados a agressões, sendo que duas a cada três dessas mulheres necessitaram de cuidados em saúde. ${ }^{7}$ Estima-se que esse número ainda possa ser maior ao considerar os casos não reportados e noticiados.

Nesse contexto, é papel do profissional de saúde acolher e promover o bem-estar das usuárias, sabendo lidar com questões de violência de gênero, identificando situações de violência ou abuso e, acima de tudo, conhecendo a forma de atender essa mulher em suas necessidades mais específicas. Entretanto, muitas vezes, a atenção dada ao problema nos setores de saúde ainda é ineficaz devido à invisibilidade da violência nos serviços de saúde. ${ }^{8}$

Estudo realizado com estudantes de enfermagem identificou um posicionamento reflexivo e estruturado, onde ele é influenciado pela mídia, mas também busca
ISSN 2236 - 198

conhecimento sobre o tema, experimenta sentimentos negativos com a impunidade do agressor e aponta o homem como o principal agressor contra as mulheres. ${ }^{9}$

Apesar de estudos como esse, a temática da violência contra a mulher deve ter uma discussão ampliada na formação dos enfermeiros, construindo, dessa maneira, um pensamento crítico e uma visão holística e humanizada acerca desse problema de saúde pública. Diante disso, formulou-se a seguinte questão de pesquisa: qual a percepção dos graduandos do curso de Enfermagem sobre a violência contra a mulher?

O objetivo desse estudo é conhecer as percepções dos graduandos em Enfermagem sobre a violência contra a mulher e sobre a atuação do enfermeiro no atendimento às mulheres em situação de violência.

\section{MATERIAIS E MÉTODOS}

Trata-se de um estudo descritivoexploratório com abordagem qualitativa. A abordagem qualitativa traduz a investigação do mundo das ações e das relações humanas, um lado que não se percebe e não se capta em equações, médias ou estatísticas, propiciando a construção de novas abordagens e a revisão e a criação de novos conceitos. ${ }^{10}$

Participaram, como sujeitos da pesquisa, 16 graduandos em Enfermagem de uma instituição de Ensino Superior privada localizada em Porto Alegre/RS. Os mesmos foram selecionados de forma aleatória e a amostra foi definida conforme critérios de saturação de dados $^{11}$. Foram 


\section{JOURNALOF \\ NURSING \\ AND HEALTH}

ISSN 2236 - 1987

adotados como critérios de inclusão: ser aluno da instituição e estar devidamente matriculado, estar cursando o último semestre do curso no período de coleta de dados e ter assinado o Termo de Consentimento Livre e Esclarecido (TCLE). Como critérios de exclusão, definiu-se: alunos que não manifestarem interesse em participar da coleta de dados.

A coleta de dados ocorreu no período de abril a junho 2016, por meio de entrevistas semiestruturadas, gravadas, com duração média de, aproximadamente, 30 minutos. As entrevistas foram realizadas na instituição de ensino, em sala reservada e sem ruídos para que não houvesse interferências no bom andamento das atividades, garantindo, assim, a preservação das informações.

As entrevistas tiveram como questões norteadoras: 0 que você entende por violência de gênero? Em que momento foi abordado e qual a importância desse tema na graduação? Qual a sua percepção sobre a atuação do enfermeiro frente às mulheres em situação de violência? Como você considera que seja o atendimento ideal à mulher em situação de violência?

Para caracterizar os participantes do estudo, foram coletados dados como: sexo, idade, estado civil, tipo e local de trabalho. Após a realização das entrevistas, as falas foram transcritas na íntegra, sendo realizados ajustes de linguagem, sem que a essência dos conteúdos fosse modificada.

Os dados foram examinados por meio de análise de conteúdo, a qual constitui-se por três fases distintas: pré-análise; exploração do material; inferência e interpretação de resultados. $\mathrm{Na}$ pré-análise, foi realizada a leitura de todo o material e a organização dos dados. Essa organização foi norteada pelos objetivos do estudo e formuladas hipóteses e feita a identificação de similaridades. Durante a exploração do material, buscou-se a elaboração de categorias para o estabelecimento dos núcleos temáticos. A interpretação e as inferências foram realizadas e fundamentadas de acordo com a literatura científica. ${ }^{10}$

Este estudo respeita os termos da resolução $n^{\circ} 466 / 12$ do Conselho Nacional de Saúde e foi autorizado pelo Comitê de Ética e Pesquisa da instituição onde foram coletados os dados, sob o parecer $n^{0} 1.503 .008$, de 14 de abril de 2016. Aos participantes do estudo, foi solicitado que assinassem o TCLE. Para garantir o sigilo e o anonimato, os entrevistados foram identificados como P1, P2, P3 e assim sucessivamente.

\section{RESULTADOS E DISCUSSÃO}

O estudo foi realizado com 16 graduandos em Enfermagem, sendo um homem e 15 mulheres. A idade dos mesmos variou de 23 a 46 anos, os quais tinham majoritariamente entre 23 a 30 anos (nove participantes). Quanto ao estado civil, 11 participantes se declararam solteiros, dois casados e três como outros. Em relação ao local de trabalho, seis são estudantes apenas, nove são trabalhadores da área da saúde e um trabalha em local não relacionado à saúde. 
A seguir, estão dispostas as categorias temáticas elaboradas a partir da análise das questões norteadoras da entrevista.

\section{Entendimento sobre violência de gênero}

Os entrevistados percebem que a violência de gênero, via de regra, volta-se não somente contra a mulher, mas contra tudo que é considerado feminino na nossa sociedade, sendo essencialmente praticada por pessoas do gênero masculino. Além disso, as falas dos entrevistados reconhecem a violência como algo próximo e recorrente em suas vidas:

Bom, gênero é homem e mulher [...] A diferença disso na violência é que as mulheres são mais sujeitas a violência. Os homens na maioria dos casos que eu ouvi, os homens se acham no poder das mulheres. Eles acham que a mulher tem que se sujeitar a eles. Para mim é isso. (P8)

Já presenciei, muito próximo, um caso de um vizinho que ele simplesmente, ele espancava a esposa, e era uma coisa, assim, absurda [...] deveras desumana, até por ele ser um homem, muito mais forte. (P9)

É qualquer violência, não necessariamente sendo física. Pode ser uma agressão verbal, qualquer tipo de agressão. A qualquer identidade de gênero também, sendo homem, mulher, travesti, gay, transexual. (P10)
Já vivenciei com os pacientes, no caso. Agressão, principalmente com gays, homossexuais e com mulheres. Com homem eu nunca vi, mas no meu trabalho eu já vi muito com mulheres. (P13)

O mundo é um espaço de relações interpessoais e o ser humano que nele habita vivencia múltiplas experiências, pois coexiste com outros seres. Sendo assim, pode se expressar de muitas maneiras, inclusive de forma conflituosa, o que pode desencadear as mais diversas manifestações, entre elas a violência, destacando a violência conjugal perpetrada contra a mulher. ${ }^{12}$

Devido à influência de questões culturais que permeiam as relações de gênero, nas quais há definição de papéis sociais para homens e mulheres, ocorre o desencadeamento de relações de desigualdades, aumentando, assim, o número de mulheres em situação de violência por envolvimento afetivo com parceiros agressivos. ${ }^{13}$

A percepção dos graduandos sobre violência de gênero foi mais abrangente e incluiu a população de lésbicas, gays, bissexuais, travestis, transexuais e transgêneros (LGBTs). Acreditamos que isso tem uma forte relação com a crença da fragilidade ou da subserviência feminina, já que a comunidade LGBT sempre é remetida ao feminino e ao vulnerável.

Sendo assim, observou-se o reconhecimento das relações de poder desiguais entre os sexos. Essas relações de poder são representadas pela ideia de posse e de superioridade física dos homens em relação às mulheres, bem como pela posição de submissão das mulheres nas relações conjugais, o 
que, em geral, ocorre por conta da cultura de gênero:

Então eu via uma mulher submissa [...] a minha mãe não sabia fazer nada que não fosse pelo olhar e pela visão dele [...], tinha que ser exatamente o que ele fazia, o que ele comprava, o que ele pensava. E a minha mãe viveu a vida toda dela assim. [...], meu pai manteve a minha mãe nessas condições, que também não deixa de ser uma violência, a gente sabe hoje que isso também é uma violência. (P12)

Sempre aquela questão do medo, da desestruturação da família, do que vão falar, do medo que ele faça alguma coisa pior, porque ele ameaçou que ele ia fazer alguma coisa pior que aquilo que ele já fazia se ela fosse denunciar ele ou se ela largasse ele, então ela aceitava. (P8)

[...] ela disse que desde sempre [sofria violência física], só que não queria se desfazer do casamento, para ela a família era muito importante, então ela aguentava, aguentava. (P1)

O patriarcado defende a ideia de superioridade do macho sobre a fêmea, do masculino sobre o feminino, sendo incompatível com a ideia de liberdade e igualdade entre os seres humanos. Sendo essa uma das maiores contradições, pois as mulheres não podem determinar sua liberdade e sua autonomia de ser humano em razão das diferenças de gênero, sem que haja repressão física e/ou psicológica. ${ }^{14}$

A banalização da violência entre casais, evidenciada pelas falas acima, denota que as mulheres em questão estão vivendo um relacionamento abusivo. Essa realidade parece acontecer em diversas partes do mundo. Um estudo realizado com mulheres da comunidade da Midwestern University, mostrou que todas as vítimas sofreram abuso físico de um parceiro íntimo. ${ }^{15}$

A ideia de patriarcado e do agressor ser íntimo da mulher vítima de violência, pode ser ilustrada pelo isolamento social. Esse tipo de situação está relacionado com a repressão que a mulher sofre do seu parceiro íntimo, o que impede um convívio social adequado. ${ }^{16}$

Os participantes desse estudo descrevem um comportamento de subjugação da mulher, principalmente dentro do âmbito familiar, onde a mulher sofre calada em nome da família, em nome dos filhos, bem como, em nome do medo.

Abordagem da violência de gênero na formação dos graduandos

Os entrevistados reconhecem a importância de desenvolver conhecimentos sobre o tema para sua formação profissional:

Estou tendo agora na cadeira de Saúde e Gênero e acho extremamente importante fazer o aluno refletir sobre os temas que estão na atualidade hoje. (P1) 
Tive em vários saraus, em disciplinas, em eventos, semanas acadêmicas [...]. Eu acho que é muito presente, muito relevante sempre falar sobre esse assunto porque [...] a gente vai lidar com esse tipo de situação. (P3)

Tive tanto na cadeira de saúde do homem e da mulher, teve outra disciplina também que teve a questão de gênero [...] Saúde e gênero. A importância dessa abordagem seria na hora de exercer a profissão, no momento que tu está ali atendendo uma paciente que sofreu uma violência, saber como orientar, saber como lidar com essa situação na hora e procurar fazer da forma mais correta possível. (P8)

Em diversos momentos tivemos essa abordagem, mas principalmente na própria disciplina de saúde do gênero, onde foi abordado as questões de homem e mulher e também a própria violência doméstica. Enfim, a importância é justamente saber os confrontos da sociedade, do impacto que causa nos próprios profissionais e em nós enquanto pessoas, o que a gente pode fazer, qual a abordagem que a gente tem que ter diante disso, nossa ética, nossa postura. Acredito que a gente tem que não ter préjulgamentos. (P16)

As falas dos estudantes retratam o reconhecimento da importância do tema. Eles identificam essa abordagem em diversas disciplinas do curso e demonstram uma grande preocupação em saber cuidar dessas vítimas quando tornarem-se profissionais.

Além das atividades acadêmicas citadas nas falas acima, destacaram-se também os estágios curriculares realizados em uma casa de acolhimento a mulheres em situação de violência na cidade de Porto Alegre/RS:

A gente também ficou sabendo que tem as casas de proteção, por causa da faculdade, dos estágios. (P12)

Saber trabalhar com essas nuances sociais do universo da saúde é uma competência que está prevista nas Diretrizes Curriculares Nacionais do curso de Graduação em Enfermagem, em seus 16 artigos, os quais orientam toda a formação para o profissional enfermeiro. Estes determinam que o egresso desse curso de graduação deve ter uma formação generalista, humanística, crítica e reflexiva. ${ }^{17}$

Além disso, as áreas de conhecimento devem direcionar o profissional para desenvolver competências e habilidades gerais nas áreas de atenção à saúde, tomadas de decisão, comunicação, administração e gerenciamento e educação permanente. Nesse sentido, são definidas competências e habilidades específicas, sendo que a formação do enfermeiro deve ser norteada por ciências biológicas e da saúde, ciências humanas e sociais e pelas ciências da Enfermagem

(fundamentos, assistência, administração e ensino em Enfermagem). ${ }^{17}$

Está previsto que a formação em Enfermagem deve atender às 


\section{JOURNALOF \\ NURSING \\ AND HEALTH}

ISSN 2236 - 198

enfrentamento da questão da violência nos serviços de saúde. Esse conteúdo deveria ser desenvolvido de forma transversal no curso. Estudo realizado com estudantes do curso de enfermagem na Universidade Federal do Rio Grande mostrou que, na visão dos alunos, as semanas acadêmicas, grupos de pesquisa, atividades e estágios, contribuíram para a construção do conhecimento sobre o tema violência contra a mulher, além das disciplinas de epidemiologia e saúde da criança e saúde da mulher. ${ }^{21}$

Percepção sobre a atuação do enfermeiro na atenção às mulheres em situação de violência

Os graduandos entrevistados entendem que o enfermeiro tem papel importante na atenção às mulheres em situação de violência, com destaque para os aspectos relacionais que envolvem habilidades de comunicação e acolhimento:

Eu acho que o enfermeiro tem que fazer a parte do acolhimento, realmente ele precisa acolher, ele precisa prestar atenção, dar atenção a essa mulher [...] então eu acho que o enfermeiro pode ser bem atuante, bem representativo nessa área. (P1)

Eu acho que o enfermeiro, além de tudo, é um educador e ele precisa orientar, seja a vítima ou a família. (P6)

0 enfermeiro tem que ser ativo para essa vítima, porque ele age tanto na questão psicológica, 


\section{ISSN 2236 - 1987}

como no amparo físico dessa mulher, da vítima em si. São feridas que devem ser cicatrizadas, acredito que o enfermeiro abrange $o$ aspecto integral dessa vitima. (P16)

Cabe aos enfermeiros, corresponsáveis pelo cuidado, realizar o acolhimento e a escuta atenciosa, entrando em contato com os relatos, facilitando a compreensão da gravidade do fenômeno e rompendo os obstáculos que impedem 0 atendimento efetivo às mulheres em situação de violência, orientando-as quanto aos seus direitos $e$ as amparando em sua tomada de decisão. ${ }^{22}$

Contudo, a partir das falas de alguns entrevistados, ficou evidente que os graduandos ainda não se percebem como parte atuante da equipe de saúde que receberá a mulher em situação de violência, sempre descrevendo a abordagem ideal na terceira pessoa, sem se incluir no atendimento:

Sinceramente, eu não sei como eles tão encarando e o que eles estão fazendo por essa mulher, eu não faço a menor ideia. (P12)

Eu acho que eles precisam se preparar cada vez mais [...], hoje ele é pouco preparado para isso, não tem tanta destreza, ou muitas vezes ele até critica a situação. (P4)

Essa falta de percepção do graduando sobre sua função no atendimento pode estar relacionada ao fato deste ainda não se sentir como parte integrante e ativa da equipe para se incluir no suporte à mulher em situação de violência.

A falta de protocolos específicos para o atendimento contribui para que os profissionais de saúde não sintam que esse atendimento seja parte inerente do exercício de suas funções, mas, sim, uma iniciativa pessoal. Essa ideia é reforçada pelo não conhecimento, por parte dos profissionais, de uma rede de atenção específica a mulheres vítimas de violência. A equipe de Enfermagem é, na maioria das vezes, a primeira que tem contato com as mulheres em situação de violência, identificando os casos de agressão e orientando a busca de soluções por meio da rede de assistência à violência, a qual compreende setores como assistência social, atenção psiquiátrica, assistência jurídica, entre outros.

\section{Considerações sobre o atendimento ideal à mulher em situação de violência}

Alguns pontos bastante citados nas entrevistas dizem respeito ao atendimento humanizado, à equipe multiprofissional e ao acolhimento às mulheres, como vemos nas falas a seguir:

Eu acho que esse atendimento tem que ser um atendimento humanizado, tu tens que dar uma assistência integral a essa paciente e apoiar ela de todas as maneiras. (P7)

Humanizado, ter ética no momento do atendimento, não expor o paciente na frente de ninguém. (P2) 


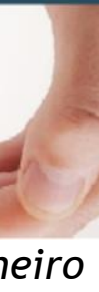

Eu acho que no primeiro momento se realiza o acolhimento, que é o que a gente realiza com todos os pacientes, mas de uma forma mais, digamos que, delicada, porque aquela pessoa tá sensibilizada. (P13)

Eu acho que deve ser um serviço multidisciplinar. Acho que tem que entrar Psicologia, psiquiatria, Enfermagem, médico, polícia, lei, acho que tem que ser uma coisa bem completa para que realmente dê certo. (P1)

o ideal seria ter um local adequado pra atender elas, privado, discreto [...]. Uma assistente social, uma psicóloga junto, técnicos que consigam receber ela bem, não só realmente a parte tecnicista que a gente conhece do trabalho, mas um lugar que apresente essa compreensão que a gente acaba aprendendo a ter, que eu aprendi a ter durante algumas aulas, uma visão maior do que elas passam e o porquê elas passam e porque elas permanecem passando por isso. Um local muito complexo. A gente não sabe se vai existir, mas idealizando esse local, eu acho que eu faria esse local assim. (P12)

A humanização do cuidado ganha destaque quando os graduandos de refletem sobre qual $o$ atendimento ideal para as mulheres. A preocupação com a abordagem dessa mulher que foi vítima de violência ganha uma atenção especial. Acreditamos que isso ocorre pelo fato da maior parte das
ISSN 2236 - 1987

estudantes de enfermagem serem mulheres e assim podem sentir-se vulneráveis ou parte daquele problema, não somente como profissional enfermeira, mas também como mulher, exercendo a empatia e a solidariedade.

A violência contra a mulher é considerada um problema social e é objeto de manifestações, pertencendo ao âmbito da segurança pública e da justiça. Sendo assim, a atenção às vítimas não é exclusividade do setor da saúde, mas também de vários outros, de forma articulada. Esse entendimento permite uma visão ampliada de saúde/doença como processo social, citando qualquer agravo e ameaça à vida, condição de trabalho, relações interpessoais, qualidade de vida e existência. Visando a superar os valores que naturalizaram as desigualdades e justificam a violência contra as mulheres, é necessário ampliar a visão do problema e da assistência em relação ao gênero. ${ }^{23}$

Para potencializar novas formas de cuidar, é necessário entender que problemas sociais interferem na saúde, recriando a linguagem pautada apenas na doença. ${ }^{20}$ Ainda é um desafio para todos os níveis de atenção oferecer atendimento humanizado às mulheres em situação de violência nos serviços de saúde. Para tal, é necessário proporcionar espaços de capacitação e suporte ao profissional para que ele se sinta apto a trabalhar com tais questões. ${ }^{21}$

É necessário buscar um novo olhar e agir no atendimento às mulheres em situação de violência garantindo uma rede de atenção. Além disso, os 


\section{JOURNALOF \\ NURSING \\ AND HEALTH}

ISSN $2236-1987$

processos de educação permanente devem ser garantidos a todos os profissionais de saúde para que se possa enfrentar a violência com autonomia, sobrepondo as desigualdades de gênero estabelecidas pela sociedade. ${ }^{24}$

\section{CONSIDERAÇÕES FINAIS}

Os acadêmicos percebem que a violência de gênero não está apenas relacionada com algo que é contra a mulher, mas também contra tudo que é considerado feminino na nossa sociedade, sendo, na maioria das vezes, praticada por pessoas do gênero masculino.

Ao mesmo tempo, observam o poder da desigualdade entre os sexos, representados pela ideia de posse e de superioridade física dos homens em relação às mulheres, bem como pela posição de submissão das mulheres nas relações conjugais em decorrência da cultura de gênero.

Nota-se que os alunos entendem a importância do papel do enfermeiro na atenção às mulheres em situação de violência, com destaque para os aspectos relacionais, os quais envolvem habilidades de comunicação e acolhimento.

Contudo, esses alunos ainda não se percebem como parte atuante da equipe de saúde que receberá a mulher em situação de violência, sempre descrevendo a abordagem ideal na terceira pessoa, sem se incluir no atendimento.

Essa falta de percepção dos entrevistados sobre sua função no atendimento se deve ao fato destes ainda não se sentirem como parte integrante e ativa da equipe para estarem inclusos no suporte à mulher em situação de violência.

Além disso, o aluno identifica a abordagem do tema violência de gênero e violência contra a mulher em mais de uma disciplina durante a graduação, o que mostra a importância da transversalidade desse tema nos currículos.

As limitações do estudo podem estar relacionadas com o fato da pesquisadora principal ser uma graduanda de enfermagem. De alguma forma, esse fato pode ter inibido alguma reflexão dos participantes do estudo. Porém, vale ressaltar que durante toda a coleta de dados, não foi possível registrar explicitamente algum desconforto, já que a confidencialidade das informações e anonimato dos participantes foram garantidos.

Pensa-se que a divulgação de estudos dessa natureza possa contribuir com a reflexão dos estudantes de Enfermagem, bem como de professores e enfermeiros, sobre a importância da discussão permanente desse tema dentro dos espaços acadêmicos e assistenciais.

\section{REFERÊNCIAS}

1 World Health Organization (WHO). Global and regional estimates of violence against women: prevalence and health effects of intimate partner violence and non partner sexual violence. Geneva: World Health Organization; 2013.

2 Delziovo CR, Berger E, Coelho S, Lindner SR. Violência sexual contra a mulher e $o$ atendimento no setor saúde 
em Santa Catarina. Ciênc. Saúde Colet. [Internet]. 2018 mai[acesso em 2018 dez 12];23(5):1687-96. Disponível em: http://www.scielo.br/pdf/csc/v23n5/ 1413-8123-csc-23-05-1687.pdf

3 Bandeira LM. Violência de gênero: a construção de um campo teórico e de investigação. Sociedade e estado [Internet]. $2014 \mathrm{mai} /$ ago[acesso em 2018 dez 13]; 29(2):449-69. Disponível em:

http://www.scielo.br/scielo.php?scrip $\mathrm{t}=\mathrm{sci}$ arttext\&pid=S0102-

69922014000200008

4 Guimarães MC, Pedroza RLS. Violência Contra a Mulher: Problematizando Definições Teóricas, Filosóficas E Jurídicas. Psicol. soc. (Online) [Internet]. 2015 mai/ago[acesso em 2018 dez 13];27(2):256-66. Disponível em: http://www.scielo.br/scielo.php?scrip $\mathrm{t}=\mathrm{sci}$ arttext\&pid=S0102-

$71822015000200256 \&$ ing=en\&nrm=iso \&tlng=pt

5 Brasil. Lei n. 11.340, de 07 agosto de 2006. Cria mecanismos para coibir a violência doméstica e familiar contra a mulher e dá outras providências [Internet]. [acesso em $2018 \mathrm{dez}$ 13]. Disponível em https://presrepublica.jusbrasil.com.b r/legislacao/95552/lei-maria-dapenha-lei-11340-06

6 Senado Federal (BR). Comissão parlamentar mista de inquérito da violência contra a mulher no Brasil: relatório final [Internet]. 2013[acesso em 2018 dez 13]. Disponível: https://www12.senado.leg.br/instituc ional/omv/entenda-aviolencia/pdfs/relatorio-final-dacomissao-parlamentar-mista-de- inquerito-sobre-a-violencia-contra-asmulheres

7 Waiselfisz JJ. Mapa da violência 2015: homicídios de mulheres no Brasil [Internet]. $1^{\mathrm{a}}$ ed. Brasília: Flacso Brasil; 2015[acesso em 2018 dez 13]. Disponível em: https: / /www.mapadaviolencia.org.br /pdf2015/MapaViolencia_2015_mulher es.pdf

8 Almeida LR, Silva ATMC, Machado LS. Jogos para capacitação de profissionais de saúde na atenção à violência de gênero. Rev. bras. educ. méd. [Internet]. 2013 jan/mar[acesso em 2018 dez 13];37(1):110-9. Disponível em:

http: / /www.scielo.br/scielo.php?scrip $\mathrm{t}=\mathrm{sci}$ _arttext\&pid=S0100-

55022013000100016

9 Silva CD, Gomes VLO. Violência contra a mulher: dimensões representacionais de discentes de enfermagem. Rev. enferm. Cent.Oeste Min. [Internet]. 2018[acesso em 2018 dez 13];8:e2528. Disponível em : http://www.seer.ufsj.edu.br/index.p $\mathrm{hp} / \mathrm{recom} /$ article/view/2528/1894

10 Minayo MCS, Gomes SFDRG. Pesquisa social: teoria, método e criatividade. 34ª ed. Petrópolis; 2015.

11 Costa LFM, Santos DF, Castro DS, Netto LA, Vasconcelos MMA, Lima EFA. Percepção de mulheres acerca da violência vivenciada. Rev. pesqui. cuid. fundam. (Online). [Internet]. 2017[acesso em $2018 \mathrm{dez}$ 13];9(1):193$9 . \quad$ Disponível em: http://www.seer.unirio.br/index.php /cuidadofundamental/article/view/53 $53 / \mathrm{pdf}$

12 Ferraz MIR, Labronici LM. Fragmentos de Corporeidades 


\section{A HEA}

femininas de violência conjugal: uma aproximação fenomenológica. Texto \& contexto enferm. $2015 \mathrm{jul} / \mathrm{set}$ [acesso em 2019 jan 07];24(3):842-9. Disponível http://www.scielo.br/pdf/tce/v24n3/ pt_0104-0707-tce-24-03-00842.pdf

13 Rodrigues VP, Machado JC, Simões AV, Pires VMM, Paiva MS, Diniz NMF. Prática de trabalhadora(e)s de saúde na atenção às mulheres em situação de violência de gênero. Texto \& contexto enferm. [Internet]. 2014 jul/set[acesso em 2018 dez 13];23(3):735-43. Disponível em: http://www.scielo.br/pdf/tce/v23n3/ pt_0104-0707-tce-23-03-00735.pdf

14 Guedes RN, Fonseca RMGS. A autonomia como necessidade estruturante para o enfrentamento da violência de gênero. Rev. Esc. Enferm. USP. [Internet]. $2011 \mathrm{dez}$ [acesso em 2018 dez 13]; 45(n.esp.2)1731-35. Disponível em: http://www.scielo.br/scielo.php?scrip $\mathrm{t}=\mathrm{sci}$ _arttext\&pid=S0080-

$62342011000800016 \& \operatorname{lng}=e n \& n r m=$ iso \&tlng=pt

15 Lim BH, Valdez CE, Lilly MM. Making Meaning Out of Interpersonal Victimization: The Narratives of IPV Survivors. Violence against women [Internet]. 2015 Sept[cited 2018 Dec 13];21(9):1065-86. Available from: https://journals.sagepub.com/doi/ab s/10.1177/1077801215590670?journal Code=vawa

16 Netto L de A, Moura MAV, Queiroz ABA, Leite FMC, Silva GF. Isolamento de mulheres em situação de violência pelo parceiro íntimo: uma condição em redes sociais. Esc. Anna Nery Rev. Enferm. [Internet]. 2017
ISSN $2236-1987$

jan/mar[acesso

18];21(1):1-8

em 2018

Disponível

dez $\mathrm{t}=\mathrm{sci}$ arttext\&pid=S1414-

$81452017000100207 \& \operatorname{lng}=e n \& n r m=i s o$ \&tlng=pt

17 Ministério da Educação (BR). Resolução CNE/CES $\mathrm{n}^{\circ} 3$, de 07 de novembro de 2001: diretrizes curriculares nacionais do curso de graduação em enfermagem. Brasília; 2001.

18 Silva PLN, Almeida SG, Martins AG, Alves ECS, Silva-Junior RF. Práticas educativas sobre violência contra a mulher na formação de universitários. Rev. bioét. (Impr.) [Internet]. 2016 mai/ago[acesso em 2018 dez 13];24(2):276-85. Disponível em: http://www.scielo.br/pdf/bioet/v24n 2/1983-8034-bioet-24-2-0276.pdf

19 Netto LA, Moura MAV, Silva GF, Penna LHG, Pereira ALF. Mulheres em situação de violência pelo parceiro íntimo: tomada de decisão por apoio institucional especializado. Rev. gaúch. enferm. [Internet]. 2015[acesso em 2018 dez 13];36(n.esp.):135-42. Disponível em: http:/ / www.scielo.br/scielo.php?scrip $\mathrm{t}=\mathrm{sci}$ arttext\&pid=S1983-

$14472015000500135 \& \operatorname{lng}=e n \& n r m=$ iso \&tlng=pt

20 Centro Universitário Metodista IPA. Projeto Pedagógico do Curso de Bacharelado em Enfermagem [Internet]. Porto Alegre; 2017[acesso em 2018 dez 13]. Disponível em: http://ipametodista.edu.br/enfermag em/projeto-pedagogico/projetopedagogico.pdf

21 Silva CD, Gomes VLO, Fonseca AD, Arejano CB, Gomes GC. Conteúdos 


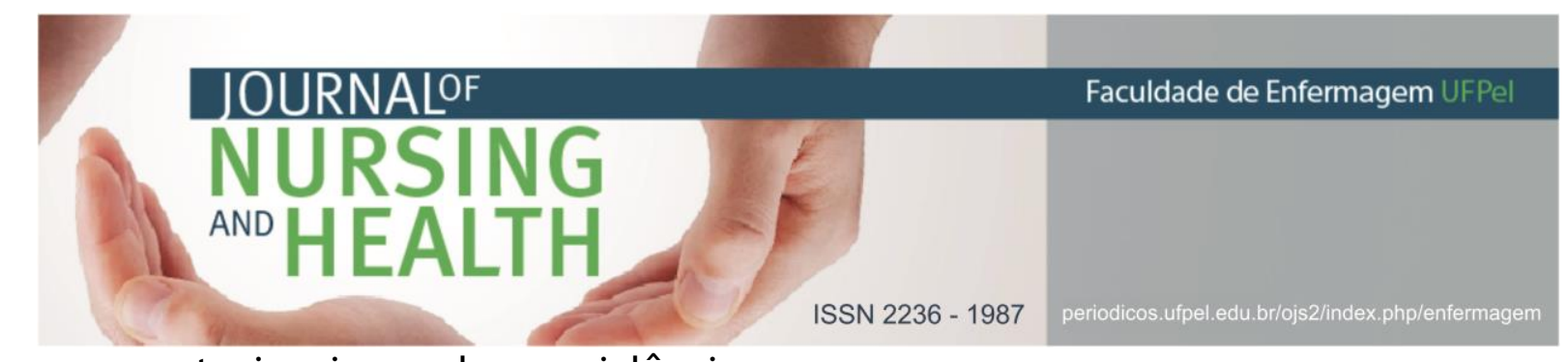

representacionais da violência doméstica contra a mulher entre discentes de enfermagem. Rev. eletrônica enferm. [Internet]. 2016[acesso em 2018 dez 13];18:e1202. Disponível em: https://revistas.ufg.br/fen/article/vi $\mathrm{ew} / 40689 / 22164$

22 Acosta DF, Gomes VLO, Fonseca AD, Gomes GC. Violência contra a mulher por parceiro íntimo: (in) visibilidade do problema. Texto \& contexto enferm. [Internet]. 2015 jan/mar[acesso em 2018 dez 13].;24(1):121-7. Disponível em:

http://www.scielo.br/pdf/tce/v24n1/ pt_0104-0707-tce-24-01-00121.pdf

23 Franzoi NM, Maria R, Serpa G, Guedes RN. Violência de gênero: concepções de profissionais das equipes de saúde da família. Rev. latinoam. enferm. (Online). [Internet]. 2011[acesso em 2018 dez 13];19(3):589-97. Disponível em: http://www.scielo.br/pdf/rlae/v19n3 /pt_19.pdf

24 Rolim HE, Rolim HV, Silva VM, Vasconcelos MS, Souza VP, Galvão MTG. Fatores associados à violência contra as mulheres na atenção primária de saúde. Rev. bras. promoç. saúde (Impr.). [Internet]. 2018[acesso em 2018 dez 13];31(1):1-9 Disponível em:

http: / / periodicos.unifor.br/RBPS/arti cle/view/6580/pdf

Data de submissão: 14/03/2018

Data de aceite: 31/08/2018

Data de publicação: 08/01/2019 